\title{
EVALUASI MUTU PANEN KELAPA SAWIT DI PT. SENTOSA KALIMANTAN JAYA
}

\section{EVALUATION OF HARVEST QUALITY IN PT. SENTOSA KALIMANTAN JAYA}

\author{
Bella Viesta Haloho ${ }^{1 *}$, Puspita ${ }^{1}$, Yuanita ${ }^{1}$ \\ ${ }^{1}$ Politeknik Pertanian Negeri Samarinda, Jl. Samratulangi PO BOX 192 Samarinda, \\ Indonesia
}

*corresponding bellaviesta872@gmail.com

\begin{abstract}
The objective of the research is to evaluate the quality of harvesting oil palm fresh fruit bunches (FFB) correlated to the harvest system implemented by two afdelings in the oil palm plantation company, PT. Sentosa Kalimantan Jaya. The research employs descriptive design, with qualitative approach, purposive sampling and snowball sampling using questionnaires, and documentation. The research reveals that the characteristics of harvesters from two afdelings are dominated from the productive age and educated at elementary school. The harvesters in afdeling 2 have more experience than afdeling 4. Afdeling 2 provides better quality of FFB than afdeling 4, it comprises ripe fruit was $86.91 \%$, abnormal was $1.07 \%$ and long stalk was $0 \%$. Meanwhile, afdeling 4 comprises raw fruit was $1.32 \%$, ripe fruit was $79.97 \%$, and over ripe fruit was $12.88 \%$. Both afdelings have permanent design of harvest system comprise the percentage of loose fruit, sengkleh stems, under pruning and over pruning which are beneath the standard. The under pruning interferes the process of cutting fruit, meanwhile the over pruning would potentially be able to reduce average bunches weight and produce male flowers dominantly. As a result, it can be deduced that the main factor affects the quality of permanent design of harvest system, and the quality of oil palm fresh fruit bunches is the harvesters' experience of work. Afdeling 2 has 6 harvesters working for $>5$ years or $46.2 \%$. The overall findings reveal that the longer harvester's working period, the labor productivity of harvesting oil palm will increase.
\end{abstract}

Keywords: Harvest Quality Evaluation, Fixed Hancak quality, FFB Quality

\section{PENDAHULUAN}

Kelapa sawit merupakan tumbuhan tropis yang tergolong dalam family palmae dan berasal dari Afrika Barat. Meskipun demikian kelapa sawit juga dapat tumbuh diluar daerah asalnya, termasuk Indonesia. Kelapa sawit merupakan tanaman dengan nilai ekonomis yang cukup tinggi karena merupakan salah satu tanaman penghasil minyak nabati (Pahan,2010).

Indonesia merupakan produsen kelapa sawit terbesar kedua di dunia setelah Malaysia. Sebanyak $85 \%$ pasar dunia kelapa sawit dikuasai oleh Indonesia dan Malaysia. Pembangunan agribisnis kelapa sawit merupakan industri yang diyakini dapat membantu pemerintah untuk mengatasi kemiskinan di indonesia. Hal ini karena industri kelapa sawit Indonesia merupakan sumberdaya alam yang dapat di perbaharui, tenaga kerja yang produktif, dan sinar matahari yang melimpah sepanjang tahun (Pahan, 2011).

Panen merupakan salah satu kegiatan yang penting pada pengelolaan tanaman kelapa sawit menghasilkan. Selain bahan tanaman dan pemeliharaan tanaman, panen juga salah satu faktor yang penting dalam menampung produksi. Keberhasilan panen akan menentukan 
Haloho, Bela, V., Puspita dan Yuanita .(2021) "Evaluasi Mutu Panen Kelapa Sawit Di PT. Sentosa Kalimantan Jaya", Jurnal Agriment, 6(2).

pencapaian produksi perkebunan. Sebaliknya kegagalan panen akan menghambat pencapain produksi perkebunan kelapa sawit. Pengelolaan tanaman yang sudah baku dan potensi produksi di pokok tinggi tidak ada artinya jika panen tidak dilaksanakan secara optimal (Sulistyo, 2010).

Pemanenan tandan buah segar (TBS) merupakan hal yang sangat penting dalam kegiatan produksi tanaman kelapa sawit. Pelaksanaan kegiatan pemanenan kelapa sawit berpengaruh langsung terhadap kuantitas dan kualitas minyak yang dihasilkan. Dalam pelaksanaan operasional panen yang perlu mendapat perhatian agar kualitas TBS dapat terjaga dengan baik adalah dengan melakukan standar panen yang benar memperhatikan kualitas panen, penempatan hancak pemanen yang benar, serta memanen buah matang panen dengan mengutip seluruh brondolan yang terlepas dari buah. Dengan melakukan panen yang baik dan benar, diharapkan akan didapatkan potensi rendemen sesuai potensi yang terkandung dalam buah (Pardamean Maruli, 2017). Pada umumnya, menurut Arikunto (2010) evaluasi sebagai sebuah proses menentukan hasil yang telah dicapai dari beberapa kegiatan yang direncanakan untuk mendukung tercapainya tujuan. Evaluasi lebih bersifat melihat kedepan nya agar jauh lebih baik dan ditunjukan pada upaya peningkatan kesempatan demi keberhasilan kegiatan. Kegiatan dalam pemanenan dimulai dari perencanaan panen, pelaksanaan panen dan evaluasi panen. Evaluasi panen adalah kegiatan pemeriksaan terhadap mutu panen dari pemanen baik itu mutu buah hasil panen maupun mutu hancak pemanen. Evaluasi panen dilakukan setiap harinya oleh Mandor panen, Asisten dan Tim Qualty Control. Pemeriksaan mutu hancak kelapa sawit dilakukan untuk mengetahui tingkat kerugiaan dan losses akibat buah tertinggal, buah matang tidak terpanen, brondolan, over pruning, pelepah sengkleh dan lainnya sedangkan pemeriksaan mutu buah dilakukan pada saat kegiatan panen berlangsung di tempat pengumpulan hasil yang dilakukan dengan cara menghitung buah mentah (unripe), matang (ripe), lewat matang (over ripe), tandan busuk dan janjang kosong (empty bunch), buah Busuk (Rotten Bunch), Tangkai Buah Panjang (Long Stalk), Buah Tidak Normal (Abnormal Bunch).

Penelitian ini bertujuan untuk mengetahui proses evaluasi mutu panen yang optimal agar produktivitas kelapa sawit meningkat. Serta untuk mengetahui kendala yang dihadapi dalam proses pemeriksaan mutu panen kelapa sawit.

\section{METODOLOGI}

A. Waktu dan Tempat Penelitian

Penelitian ini akan dilaksanakan di PT. Sentosa Kalimantan Jaya. Waktu penelitan ini dilaksanakan selama 2 bulan dimulai dari tanggal 18 September 2020 sampai dengan tanggal 18 November 2020, meliputi pengumpulan alat dan bahan, penelitian dan pengambilan data.

B. Alat dan Bahan

Alat yang digunakan yaitu alat tulis,camera,laptop dan recorder, sedangkan bahan yang digunakan yaitu karung brondolan, dokumentasi atau arsip perusahaan dan literatur atau pustaka

C. Metode Pengambilan Data

Pengumpulan data yang dilakukan oleh penulis meliputi pengambilan data primer ataupun data sekunder. Data primer adalah data yang diambil secara langsung oleh peneliti kepada sumbernya tanpa ada perantara meliputi wawancara, 
observasi dan dokumentasi. Sedangkan data sekunder adalah sumber data tidak langsung yang mampu memberikan tambahan serta penguatan terhadap data penelitian meliputi dokumen perusahaan dan studi pustaka.

D. Prosedur Kerja

Pelaksanaan penelitian ini terdiri dari empat tahap utama yaitu, persiapan, peninjauan lapangan, pengambilan data, dan pengolahan data. Adapun uraian penelitian sebagai berikut.

\section{Persiapan}

Pada tahap ini, hal yang dilakukan yaitu persiapan alat dan bahan yang akan digunakan pada saat wawancara, observasi lapangan, dan dokumentasi.

2. Peninjauan lapangan

Peninjauan lapangan meliputi kegiatan penentuan lokasi afdeling yang akan dijadikan objek untuk penelitian.

3. Pengambilan data

Kegiatan yang dilakukan dalam pengambilan data penelitian ini yaitu mengunakan data primer dan data sekunder.

4. Pengolahan data

Dalam pengolahan data tersebut antara lain, memeriksa data yang telah didapat dari lapangan, kemudian diolah di komputer atau laptop untuk dianalis.

\section{HASIL DAN PEMBAHASAN}

1. Karakteristik Responden Responden dalam penelitian ini adalah seluruh karyawan panen PT. Sentosa Kalimantan Jaya yang berjumlah 26 karyawan dari afdeling 2 sebanyak 13 karyawan dan afdeling 4 sebanyak 13 karyawan. Adapun gambaran karakteristik responden dalam penelitian ini meliputi usia, pengalaman kerja a. Usia dan tingkat pendidikan.

Dalam penelitian ini juga diukur parameter usia dari karyawan yang menjadi objek penelitian. Tabel 1 memperlihatkan bahwa dari 26 responden karyawan panen yang dikelompokkan berdasarkan usia di PT. SKJ, peresentase usia karyawan panen yang tertinggi pada Afdeling 2 yaitu usia 31-40 tahun sebesar $53.8 \%$ atau 7 orang dan pada Afdeling 4 usia tertinggi yaitu usia 20-30 tahun sebesar $46.1 \%$ atau 6 orang sedangkan peresentase usia karyawan panen yang terendah pada Afdeling 2 dan Afdeling 4 yaitu usia lebih dari (>) 50 tahun sebesar $7.7 \%$ atau sebanyak 1 orang.

Tabel 1. Distribusi responden berdasarkan usia

\begin{tabular}{cccccc}
\hline \multirow{2}{*}{ No } & Usia & \multicolumn{2}{c}{ Afdeling } & \multicolumn{2}{c}{ Persentase(\%) } \\
\cline { 3 - 6 } & (Tahun) & $\mathbf{2}$ & $\mathbf{4}$ & $\mathbf{2}$ & $\mathbf{4}$ \\
\hline 1 & $20-30$ & 2 & 6 & 15.4 & 46.1 \\
2 & $31-40$ & 7 & 3 & 53.8 & 23.1 \\
3 & $41-50$ & 3 & 3 & 23.1 & 23.1 \\
4 & $>50$ & 1 & 1 & 7.7 & 7.7 \\
\hline \multicolumn{2}{c}{ Jumlah } & 13 & 13 & 100 & 100 \\
\hline
\end{tabular}

Berdasarkan data penelitian karyawan panen pada Afdeling 2 dan Afdeling 4 di PT. SKJ memperlihatkan bahwa nilai presentase usia karyawan yang tertinggi pada Afdeling 2 antara 3140 tahun sebesar $53.8 \%$ dan Afdeling 4 antara $20-30$ tahun sebesar $46.1 \%$. Hal ini menunjukkan bahwa karyawan kedua Afdeling memasuki usia produktif dalam melakukan kegiatan panen, sehingga karyawan mampu menghasilkan produktivitas yang tinggi untuk perusahaan. Menurut pendapat Simamora dkk., (2016) yang menyatakan bahwa pekerjaan untuk memanen Tandan Buah Segar (TBS) tergolong ke dalam pekerjaan yang berat dan memerlukan fisik yang baik dan semangat kerja yang tinggi dalam rangka mengembangkan potensi usaha produksi dalam bekerja dan mencapai target yang telah ditentukan oleh perusahaan, sehingga banyak diisi 
Haloho, Bela, V., Puspita dan Yuanita .(2021) "Evaluasi Mutu Panen Kelapa Sawit Di PT. Sentosa Kalimantan Jaya", Jurnal Agriment, 6(2).

oleh kelompok usia yang tergolong usia produktif muda.

\section{b. Lama Kerja}

Dalam hasil penelitian ini, masa kerja tenaga kerja panen berkisar antara $<1$ tahun hingga $>5$ tahun.

Tabel 2. memperlihatkan bahwa dari 26 responden yang dikelompokkan berdasarkan lama bekerja di perusahaan PT. SKJ, peresentase Afdeling 2 paling banyak responden bekerja $>5$ tahun sebesar $46.2 \%$ atau sebanyak 6 orang dan pada Afdeling 4 paling banyak responden bekerja 3-4 tahun sebesar $46.2 \%$ atau sebanyak 6 orang sedangkan di Afdeling 4 tidak ada karyawan panen yang memiliki lama kerja (>)5 tahun.

Tabel 2. Distribusi responden berdasarkan usia

\begin{tabular}{cccccc}
\multicolumn{6}{c}{ Lama } \\
No & $\begin{array}{c}\text { Kama } \\
\text { Kerja }\end{array}$ & \multicolumn{2}{c}{ Afdeling } & \multicolumn{2}{c}{ Persentase(\%) } \\
\cline { 3 - 6 } (Tahun) & $\mathbf{2}$ & $\mathbf{4}$ & $\mathbf{2}$ & $\mathbf{4}$ \\
\hline 1 & $<1$ & 3 & 5 & 23.1 & 38.5 \\
2 & $1-2$ & 2 & 2 & 15.4 & 15.4 \\
3 & $3-4$ & 2 & 6 & 15.4 & 46.2 \\
4 & $>5$ & 6 & 0 & 46.2 & 0 \\
\hline \multicolumn{2}{c}{ Jumlah } & 13 & 13 & 100 & 100 \\
\hline
\end{tabular}

Hasil data penelitian bahwa dari 26 responden kedua afdeling yang dikelompokkan berdasarkan lama kerja di PT. SKJ. Diketahui bahwa prsentase pada Afdeling 2 paling tinggi berkerja selama lebih dari (>) 5 tahun sebesar 46.2\% sedangkan pada Afdeling presentase paling tinggi berkerja selama 3-4 tahun sebesar $46.2 \%$ dan pada Afdeling 4 tidak ada karyawan panen yang bekerjanya selama lebih dari (>) 5 tahun. Hal ini menujukan Semakin lama masa kerja seorang tenaga kerja, semakin terampil melakukan pekerjaan dan semakin sempurna pola berfikir dan sikap dalam bertindak untuk mencapai tujuan yang ditetapkan perusahaan (Prasetia dan Sonny, 2015).

c. Pendidikan
Pendidikan yang dimaksud dalam penelitian ini adalah pendidikan formal yang dimiliki karyawan panen. Tabel 3 memperlihatkan bahwa dari 26 Responden yang dikelompokkan berdasarkan tingkat pendidikan saat ini, paling tinggi tingkat pendidikan pada Afdeling 2 dan Afdeling 4 yaitu seluruhnya tingkat SD sebesar $100 \%$ atau sebanyak 13 orang. perusahaan tidak menetapkan tingkat pendidikan untuk menjadi tenaga kerja.

Tabel 3. Distribusi responden berdasarkan pendidikan

\begin{tabular}{cccccc} 
& Tingkat & \multicolumn{2}{c}{ Afdeling } & \multicolumn{2}{c}{ Persentase(\%) } \\
\cline { 3 - 6 } No & Pendidikan & $\mathbf{2}$ & $\mathbf{4}$ & $\mathbf{2}$ & $\mathbf{4}$ \\
\hline 1 & SD & 13 & 13 & 100 & 100 \\
2 & SLTP & 0 & 0 & 0 & 0 \\
3 & SLTA & 0 & 0 & 0 & 0 \\
\hline & Jumlah & 13 & 13 & 100 & 100 \\
\hline
\end{tabular}

Adapun tingkat pendidikan karyawan panen dari 26 responden kedua Afdeling seluruhnya karyawan panen berasal dari tingkat SD sebesar $100 \%$. Hasil tersebut menujukkan bahwa perusahaan tidak mempertimbangkan latar belakang pendidikan karyawan panen karena pekerjaan panen hanya memerlukan fisik yang baik dan semangat kerja yang tinggi untuk mencapai target yang telah ditetapkan oleh perusahaan. Menurut Suyastiri (2007) dalam Lubis dan Septi (2016) menyatakan bahwa keterampilan, kekuatan fisik, dan ketelitian sangat diutamakan dalam kegiatan panen kelapa sawit

\section{Sistem Panen Hancak Tetap} Hancak panen yang digunakan di kebun PT. SKJ khususnya di Afdeling 2 dan 4 adalah sistem panen hancak tetap. Ketentuan sistem hancak tetap yang penulis teliti di kedua Afdeling tertera pada tabel 4. Berdasarkan tabel 4 di atas bahwa 16 uraian tersebut adalah ketentuan dari standar perusahaan yang penulis dapatkan hasil pengambilan data 
dokumen Perusahaan dan hasil pengamatan secara langsung di lokasi penelitian. Kedua Afdeling memiliki tahun tanam yang berbeda yaitu Afdeling 2 tahun tanam 2009 atau umur tanaman yaitu 11 tahun dan Afdeling 4 tahun tanam 2012 yaitu 8 tahun sedangkan jumlah basis janjang pemanen Afdeling 2 yaitu 125 janjang dengan luasan Afdeling 32 ha dan Afdeling 4 jumlah basis janjang pemanen 181 janjang dengan luasan 34 ha. Jumlah blok saat penelitiian yaitu 2 blok pada Afdeling 2 dan 2 blok pada Afdeling 4 dengan masing-masing SPH 140, jarak tanam 9,2 $\mathrm{m}$, jarak antar baris 7,97 , jumlah rata-rata Hancak sebanyak 13 hancak dan $62 \mathrm{TPH}$. Panen menggunakan rotasi panen yaitu 10 hari yang artinya panen Tabel 4. Ketentuan sistem panen yang diterapkan di lokasi penelitian

\begin{tabular}{clll}
\hline No & Uraian & Afdeling 2 & Afdeling 4 \\
\hline 1 & Tahun Tanam (TT) & 2009 & 2012 \\
2 & Umur tanaman & 11 tahun & 8 tahun \\
3 & Jumlah basis janjang & 135 & 181 \\
4 & Jumlah blok yang diteliti & 2 blok & 2 blok \\
5 & Asisten afdeling & Muhammad Ayis & Junardi \\
6 & Mandor & Muh. Taufik & Akmal Abdillah \\
7 & Pemanen & 13 & 13 \\
8 & Luas (ha) Rata-rata & 32 & 34 \\
9 & SPH (pokok/ha) & 140 & 140 \\
10 & Jarak tanam & 9.2 meter & 9.2 meter \\
11 & Jarak antar baris & 7.97 & 7.97 \\
12 & Jumlah Rata-rata Hancak per Blok & 13 hancak & 13 hancak \\
13 & Luasan Hancak $\quad$ Rata-rata & 2 ha & 2 ha \\
& Pemanen & & \\
14 & Jumlah Rata-rata TPH per Blok & 62 TPH & 62 TPH \\
15 & Sistem Hancak & Hancak tetap & Hancak tetap \\
16. & Rotasi & 10 Hari & 10 Hari \\
\hline
\end{tabular}

3. Jumlah Kualitas TBS

Pemeriksaan kualitas TBS dilakukan pada saat kegiatan panen berlangsung di tempat pengumpulan hasil yang dilakukan oleh tim Quality Control (QC) dengan cara menghitung buah mentah, buah masak, buah lewat masak, abnormal, tangkai panjang

Berdasarkan tabel 5, bahwa hasil penelitian kualitas TBS pada Afdeling 2 dilaksanakan sepuluh hari dalam satu minggu setengah.

Sistem hancak panen pada kedua Afdeling di lokasi menggunakan sistem hancak tetap. Hancak tetap adalah lokasi panen tertentu setiap pemanen sehingga kegiatan panen selalu dilakukan pada tempat yang sama oleh setiap pemanen (Sunarko,2010) Hasil penelitian yang penulis dapatkan sesuai pada tabel 4 dapat dijelaskan bahwa kedua Afdeling memiliki perbedaan tahun tanam Sehingga dapat dikatakan bahwa standar kualitas TBS di kedua Afdeling memiliki kualitas yang belum sesuai standar perusahaan.

menujukkan kualitas yang jauh lebih baik, dimana kriteria masih sesuai standar perusahaan yaitu warna buah orange kemerahan,lepas brondolan sebanyak 5 brondolan perjanjang kurang dari 10 hari dan tingkat kematangan buah terdapat pada fraksi 2 dan 3 membrondol maksimun $50 \%$. Pada Afdeling 2 jumlah buah masak 86.91\%, Abnormal 1.07\% dan Tangkai Panjang 0\%. Sedangkan 
Haloho, Bela, V., Puspita dan Yuanita .(2021) "Evaluasi Mutu Panen Kelapa Sawit Di PT. Sentosa Kalimantan Jaya", Jurnal Agriment, 6(2).

pada Afdeling 4 menunjukkan kualitas yang kurang baik, karena masih adanya kriteria yang tidak sesuai standar yang ditentukan perusahaan yaitu buah mentah $1.32 \%$, masak $79.97 \%$ dan lewat masak sebesar $12.88 \%$. Permasalahan kualitas tandan buah segar di kedua afdeling yaitu buah mentah dan buah lewat masak.

Faktor penyebab kurangnya presentase buah masak yang terpanen pada Afdeling 4 adalah organisasi panen yang kurang baik dan kurangnya pemahaman tentang kriteria buah. Faktor lainnya kurangnya presentase buah masak yaitu pengaruhnya pada usia pemanen antara 20-30 tahun sebesar $46.1 \%$ atau sebanyak 6 orang. Dari pernyataan tersebut dapat disimpulkan bahwa usia pemanen yang berusia muda biasanya belum mengetahui buah yang layak untuk dipanen atau kriteria buah masak seperti buah masak dengan brondolan 1 atau 2 belum bisa dinyatakan buah masak. Faktor penyebab besarnya presentase buah mentah yaitu produksi buah yang menurun,over pruning yang berlebihan yang akan berdampak hasil fotosintesis pelepah yang ada dan pertumbuhan buah jadi terganggu.faktor lainnya yaitu besar presentase buah mentah yaitu pengaruh pada lama kerja pemanen menujukkan bahwa pada afdeling 2 lebih lama bekerja selama $>5$ tahun sebesar 6 orang. Dari pernyataan tersebut dapat disimpulkan bahwa lama bekerja pemanen dengan masa kerja yang lama memiliki pengalaman, lebih terampil menyelesaikan pekerjaannya, lebih paham tugasnya dan lebih taat terhadap peraturan yang diterapkan perusahaan.

Tabel 5. Kualitas TBS pada Afdeling 2 dan 4

\begin{tabular}{cccccccc}
\hline Afdeling & Blok & $\begin{array}{c}\text { Buah } \\
\text { Mentah } \\
\text { (Unripe) } \\
\mathbf{0 \%}\end{array}$ & $\begin{array}{c}\text { Buah } \\
\text { Masak } \\
\text { (Ripe) } \\
>\mathbf{8 5 \%}\end{array}$ & $\begin{array}{c}\text { Buah } \\
\text { Lewat } \\
\text { Masak } \\
\text { (Over Ripe) } \\
<7 \%\end{array}$ & $\begin{array}{c}\text { Abnormal } \\
<5 \%\end{array}$ & $\begin{array}{c}\text { Tangkai } \\
\text { Panjang } \\
\text { (Long Stalk) } \\
<5 \%\end{array}$ & $\begin{array}{c}\text { Total } \\
\text { Janjang }\end{array}$ \\
\hline 2 & 146 & 1.06 & 89.75 & 6.71 & 1.41 & 0 & 283 \\
& $\mathrm{~J} 49$ & 0 & 84.06 & 8.33 & 0.72 & 0 & 276 \\
\hline Rata & & $\mathbf{0 . 5 3}$ & $\mathbf{8 6 . 9 1}$ & $\mathbf{7 . 5 2}$ & $\mathbf{1 . 0 7}$ & $\mathbf{0}$ & $\mathbf{5 5 9}$ \\
\hline 4 & $\mathrm{C} 45$ & 2.28 & 83.27 & 9.51 & 3.80 & 0 & 263 \\
& $\mathrm{D} 45$ & 0.35 & 76.68 & 16.25 & 0.35 & 0 & 283 \\
\hline Rata & & $\mathbf{1 . 3 2}$ & $\mathbf{7 9 . 9 7}$ & $\mathbf{1 2 . 8 8}$ & $\mathbf{2 . 0 8}$ & $\mathbf{0}$ & $\mathbf{5 4 6}$ \\
\hline
\end{tabular}

4. Nilai Kualitas Hancak

Pemeriksaan kualitas hancak dilakukan setelah kegiatan panen selesai. Pemeriksaa kualitas hancak harus dilaksanakan agar kualitas panen tetap terjaga dengan baik dengan tujuan ada atau tidaknya sumber kehilangan hasil (losses) dan tingkat keefektifan panen pada setiap panen yang dikerjakan.

Berdasarkan hasil penelitian pada dua Afdeling menunjukkan nilai kualitas hancak yang tidak sesuai standar perusahaan dimana pada Afdeling 2 menunjukkan jumlah presentase brondolan tinggal yang terbilang tinggi yaitu $72,85 \%$, pelepah sengkleh $1,20 \%$, under pruning $1.81 \%$, over pruning $0.41 \%$, meskipun buah tinggal dan buah matahari sudah sesuai standar perusahaan yaitu $0 \%$. Sedangkan pada Afdeling 4 menunjukkan presentase brondolan tinggal yang juga terbilang tinggi yaitu $22.25 \%$, buah tinggal $0.37 \%$, pelepah sengkleh $2.97 \%$, under pruning $6.92 \%$, dan over pruning $5.09 \%$. Permasalahan 
yang terjadi pada kedua Afdeling yaitu pada brondolan tinggal,buah tinggal,pelepah sengkleh,under pruning dan over pruning.

Secara umum losses terbesar berasal dari banyaknya brondolan yang tertinggal di piringan ataupun tph. faktor penyebab terjadinya kehilangan produksi adalah 3 faktor yaitu kondisi tanaman, manusia dan lahan. Pemanen yang menyebabkan kehilangan hasil seperti TBS dan brondolan tertinggal akan kena sanksi berupa teguran dan denda. Pemberian sanksi ini bertujuan agar losses dapat dimininalisir sekecil mungkin.

Tabel 6. Nilai Kualitas Hancak Afdeling 2 dan Afdeling 4

\begin{tabular}{cccccccc}
\hline Afdeling & Blok & $\begin{array}{c}\text { Brondolan } \\
\text { Tinggal } \\
\mathbf{0} \%\end{array}$ & $\begin{array}{c}\text { Buah } \\
\text { Tinggal } \\
\mathbf{0} \%\end{array}$ & $\begin{array}{c}\text { Buah } \\
\text { Matahari } \\
\mathbf{0 \%}\end{array}$ & $\begin{array}{c}\text { Pelepah } \\
\text { Sengkleh } \\
\mathbf{0} \%\end{array}$ & $\begin{array}{c}\text { Under } \\
\text { Pruning } \\
<\mathbf{2 \%}\end{array}$ & $\begin{array}{c}\text { Over } \\
\text { Pruning } \\
\mathbf{0} \%\end{array}$ \\
\hline 2 & 146 & 93.30 & 0 & 0 & 2.00 & 3.60 & 0.80 \\
& $\mathrm{~J} 49$ & 52.40 & 0 & 0 & 0.39 & 0.02 & 0.01 \\
\hline Rata & & $\mathbf{7 2 . 8 5}$ & $\mathbf{0}$ & $\mathbf{0}$ & $\mathbf{1 . 2 0}$ & $\mathbf{1 . 8 1}$ & $\mathbf{0 . 4 1}$ \\
\hline 4 & $\mathrm{C} 45$ & 19.70 & 0 & 0 & 0.40 & 1.20 & 0 \\
& D45 & 24,80 & 0.73 & 0 & 5.45 & 11.63 & 10.18 \\
\hline Rata & & $\mathbf{2 2 . 2 5}$ & $\mathbf{0 . 3 7}$ & $\mathbf{0}$ & $\mathbf{2 . 9 7}$ & $\mathbf{6 . 9 2}$ & $\mathbf{5 . 0 9}$ \\
\hline
\end{tabular}

Faktor penyebab besarnya presentase brondolan tinggal pada kedua Afdeling yaitu kelalaian pembrondol dan kondisi piringan kurang baik yaitu banyak ditumbuhi gulma sehingga menyulitkan pembrondol dalam mengutip brondolan dan juga disebabkan oleh kelalaian pemanen (cutter). Pemanen tidak mengutip brondolan yang tertinggal di bawah janjang panen dan brondolan yang tercecer akibat penggancuan dan pengangkutan mamakai arco, oleh karena itu perlu dilakukan peningkatan pengawasan panen untuk meminimalkan kehilangan panen. Faktor lainnya yang menyebabkan besar presentase brondolan tinggal yaitu lama kerja karyawan pemanen pada Afdeling 4 Hasil tersebut menunjukkan bahwa pemanen pada Afdeling 2 lebih berpengalaman dari pemanen Afdeling 4. Sebagaimana dinyatakan oleh Bindrianes dkk., (2017) bahwa lama kerja mencerminkan pengalaman yang dimiliki pemanen dalam memanen TBS. Pemanen yang sudah lama bekerja lebih mampu mengenal seluk beluk permasalahan yang dihadapi, sehingga lebihmampu untuk mengatasinya. Faktor lainnya yang menyebabkan brondolan tinggal tinggi pada kedua Afdeling yaitu terdapat tingkat pendidikan pemanen berdasarkan berdasarkan tabel 4 menunjukkan bahwa Afdeling 2 dan Afdeling 4 memiliki karyawan panen yang pendidikannya tingkat SD sebesar $100 \%$ atau sebanyak 13 orang. Dari pernyataan tersebut dapat disimpulkan bahwa tingkat pendidikan menentukan seseorang dalam menerima informasi dan pengetahuan. Karyawan pemanen yang memiliki tingkat pendidikan yang lebih tinggi akan lebih tanggap terhadap informasi yang didapat dalam memanen.

Faktor penyebab buah tinggal adalah kondisi lereng serta pasar pikul yang kurang baik yang menyulitkan pemanen menurunkan TBS sehingga banyak buah yang tidak terpanen atau buah tinggal dipokok, masih adanya pemanen yang lupa membawa buah yang telah dipanen ke TPH. Pada Afdeling 4 presentase buah tinggal sebesar $0.37 \%$. faktor penyebab besarnya presentase 
Haloho, Bela, V., Puspita dan Yuanita .(2021) "Evaluasi Mutu Panen Kelapa Sawit Di PT. Sentosa Kalimantan Jaya", Jurnal Agriment, 6(2).

buah tinggal yaitu usia tanaman yang berbeda sehingga buah pada afdeling 4 lebih banyak yang membuat karyawan malas memanen jika kondisi lahan yang kurang baik dan malasnya mandor memeriksa hancak pemanennya dan juga usia pemanen dapat menyebabkan buah tinggal karena usia muda karyawan pemanen biasanya banyak yang mengalami kekecewaan,kemalasan yang menimbulkan produktivitas menurun. Faktor penyebab terjadinya over pruning karena kurangnya pengetahuannya pemanen dalam memelihara songgo pada tanaman dan kurangnya kejelian pemanen dalam menilai kriteria buah sehingga pelepah terlajur dipotong padahal belum membrondol. Faktor karakteristik responden yaitu tingkat pendidikan, tingkat pendidikan keseluruhan pemanen pada kedua Afdeling yaitu SD sehingga pemanen kurang motivasi dan berinisiatif dalam memelihara hancak mereka masing-masing. Dampak over pruning adalah peningkatan gugurnya bunga betina,penurunan bunga jantan dan penurunan bobot janjang rata-rata Sedangkan under pruning dampaknya dapat terganggunya pelaksanaan potong buah.

\section{KESIMPULAN}

Karakteristik responden karyawan panen kedua Afdeling menunjukkan nilai presentase memasuki usia produktif dan tingkat pendidikan yaitu tingkat SD sedangkan karakteristik lama kerja Afdeling 2 menunjukan nilai presentase lebih berpengalaman dibandingkan Afdeling 4. Evaluasi panen adalah kegiatan pemeriksaan terhadap mutu panen dari pemanen baik itu mutu buah maupun mutu hancak pemanen. Hasil dari evaluasi kualitas TBS pada Afdeling 2 jauh lebih baik karena jumlah keseluruhan kualitas TBS yang sudah sesuai standar perusahaan yaitu buah masak sebesar $86.91 \%$, abnormal sebesar $1.07 \%$ dan tangkai panjang sebesar $0 \%$. sedangkan pada Afdeling 4 kurang baik karena buah mentah sebesar $1.32 \%$ buah masak sebesar $79.97 \%$ dan buah lewat masak sebesar $12.88 \%$ melebihi standar perusahaan. Kedua Afdeling memiliki hancak tetap dan hasil evaluasi kualitas hancak pada kedua Afdeling menunjukkan nilai presentase tidak sesuai standar perusahaan karena jumlah presentase brondolan tinggal,pelepah sengkleh, under pruning dan over pruning sangat jauh dari standar ketentuan perusahaan. Dampak resiko dari under pruning adalah dapat terganggunya pelaksanaan potong buah sedangkan dampak resiko dari over pruning berpotensi terjadinya penurunan BJR, pembentukan bunga jantan lebih dominan. Fator yang utama yang mempengaruhi mutu hancak dan mutu buah yaitu lama kerja dimana pada Afdeling 2 paling lama berkerja selama $>5$ tahun sebesar $46.2 \%$ sebanyak 6 orang yaitu semakin lama masa kerja pemanen maka produktivitas kerja tenaga kerja panen kelapa sawit akan meningkat dan manajemen panen perlu ditingkatkan karena jumlah tenaga kerja yang kurang, rendahnya kesadaran tenaga kerja, tidak tercapainya standar kematangan buah yang dipanen.

\section{DAFTAR PUSTAKA}

Arikunto, S. (2018). Dasar-Dasar Evaluasi Pendidikan. Jakarta: Bumi Aksara

Bindrianes, S., Kemala, N., dan Busyra, R. G. (2017). Produktivitas Tenaga Kerja Panen Kelapa Sawit dan FaktorFaktor Yang Mempengaruhi Pada Unit Usaha Batanghari di PTPN VI Jambi. Jurna Agribisnis Sumatera Utara, 74-85. (diunduh 18 Agustus 2020).

Pahan, lyung. (2010). Panduan Lengkap Kelapa Sawit Manajemen Agribisnis darl Hulu hingga Hilir. Penebar Swadaya. Jakarta

Pahan, lyung. (2011). Panduan Lengkap Kelapa Sawit Manajemen Agribisnis dari Hulu hingga Hilir. Edisi IX. Penebar Swadaya. Jakarta. 411 hal. 
Pardamean, Maruli. 2017. Best Management Practice Kelapa Sawit. Yogyakarta: Penerbit Andi Offset.

Prasetia, Dimas, Sony Sumarsono dan M. Adenan. (2015). Analisis Faktor yang mempengaruhi Pendapatan Tenaga Kerja Wanita Pada Sektor Industri Manik-Manik di Desa Tutul Kecamatan Balung Kabupaten Jember. Skripsi. Universitas Jember.

Septi Nur Afifah dan Iskandar Lubis. (2016). Faktor Penentu Produktivitas Tenaga Kerja Panen Kelapa Sawit Kalimantan Timur. Kalimantan Timur.

Simamora A.W.F., Sayekti W.D., Situmorang A. (2016). Produktivitas Tenaga Kerja Pemanen di PT. Perkebunan Nusantara VII Unit Kebun Kelapa Sawit Rejosari. http://jurnal.fp.unila.ac.id (diunduh 16 Agustus 2020).

Sulistyo, B., A. Purba., D.Siahaan., J. Efendi., A. Sidik. (2010). Budidaya Kelapa Sawit. PT Balai Pustaka, Jakarta.

Sunarko I. (2010). Budidaya dan Pengelolaan Kebun Kelapa Sawit dengan Sistem Kemitraan. Edisi II. Agomedia Pustaka. Jakarta Selatan. 178 hal. 